\title{
A novel high-power pulse PECVD method
}

\author{
Henrik Pedersen, Petter Larsson, Asim Aijaz, Jens Jensen and Daniel Lundin
}

\section{Linköping University Post Print}

N.B.: When citing this work, cite the original article.

Original Publication:

Henrik Pedersen, Petter Larsson, Asim Aijaz, Jens Jensen and Daniel Lundin, A novel highpower pulse PECVD method, 2012, Surface \&amp; Coatings Technology, (206), 22, 45624566.

http://dx.doi.org/10.1016/j.surfcoat.2012.05.007

Copyright: Elsevier

http://www.elsevier.com/

Postprint available at: Linköping University Electronic Press

http://urn.kb.se/resolve?urn=urn:nbn:se:liu:diva-81223 


\section{A novel High-Power Pulse PECVD method}

Henrik Pedersen ${ }^{1, *}$, Petter Larsson ${ }^{1}$, Asim Aijaz $^{1}$, Jens Jensen ${ }^{1}$, Daniel Lundin ${ }^{1,2}$

${ }^{1}$ Department of Physics, Chemistry and Biology,

Linköping University, SE-581 83 Linköping, Sweden

${ }^{2}$ Laboratoire de Physique des Gaz et Plasmas, UMR 8578 CNRS,

Université Paris Sud-XI , F-91405 Orsay Cedex, France

*Corresponding author; e-mail: henke@ifm.liu.se

Phone: +4613286847

Fax: +4613137568 


\section{Abstract}

A novel plasma enhanced CVD (PECVD) technique has been developed in order to combine energetic particle bombardment and high plasma densities found in ionized PVD with the advantages from PECVD such as a high deposition rate and the capability to coat complex and porous surfaces. In this PECVD method, an ionized plasma is generated above the substrate by means of a hollow cathode discharge. The hollow cathode is known to generate a highly ionized plasma and the discharge can be sustained in direct current (DC) mode, or in high-power pulsed (HiPP) mode using short pulses of a few tens of $\mu$ s. The latter option is similar to the power scheme used in high power impulse magnetron sputtering (HiPIMS), which is known to generate a high degree of ionization of the sputtered material, and thus providing new and added means for the synthesis of tailor-made thin films. In this work amorphous carbon coatings containing copper, have been deposited using both HiPP and DC operating conditions. Investigations of the bulk plasma using optical emission spectroscopy verify the presence of $\mathrm{Ar}^{+}, \mathrm{C}^{+}$as well as $\mathrm{Cu}^{+}$when running in pulsed mode. Deposition rates in the range $30 \mu \mathrm{m} / \mathrm{h}$ have been obtained and the amorphous, copper containing carbon films have a low hydrogen content of $4-5$ at\%. Furthermore, the results presented here suggest that a more efficient PECVD process is obtained by using a superposition of HiPP and DC mode, compared to using only DC mode at the same average input power.

Keywords: PECVD, hollow cathode, pulsed plasma discharges, amorphous carbon 


\section{Introduction}

A chemical vapor deposition (CVD) process that uses the energy from a plasma discharge, rather than thermal energy supplied by high process temperature, to activate the gas phase chemistry is denoted Plasma Enhanced CVD (PECVD) or alternatively Plasma Activated CVD (PACVD). In a PECVD process, the precursor gases are cracked by the energetic species (predominantly through electron impact collisions [1]) in the plasma at a low overall process temperature, which means that low substrate temperatures can be achieved during deposition. This enables deposition on temperature sensitive substrates and the use of precursors with low reactivity. A PECVD system is classified as a direct plasma process, when the substrate to be coated is placed directly in the plasma discharge, or a remote plasma process, when the plasma is created at some distance from the substrate. The plasma is commonly created by applying an electric field across a volume of gas using for example an RF glow discharge [2, 3].

Another approach to ignite a plasma is to use a hollow cathode discharge [4, 5]. The hollow cathode traps electrons in a hollow cylinder or between two parallel plates. It works like two electrostatic mirrors reflecting electrons between the sheaths until they are thermalized through collisions, and thus increasing the plasma density and the probability of ionizing any material passing through [6]. The hollow cathode approach has previously been utilized in PECVD processes for the deposition of amorphous carbon films and the process has been studied both by experiments and modeling [7] and up-scaling by the use of an array of hollow cathodes has been demonstrated [8]. Coating of the inside of metallic tubes with amorphous carbon has been done by using the tube itself as a hollow cathode and 
introducing the process gases in the tube [9]. The hollow cathode PECVD method has also been used for amorphous CN films [10].

During the last 15-20 years, the field of ionized physical vapor deposition (iPVD) has grown rapidly [11] especially by the introduction of the high power impulse magnetron sputtering (HiPIMS) technique, also known as high power pulsed magnetron sputtering (HPPMS), which uses high-power pulses at a low duty factor $(<10 \%)$ and low frequency $(<10 \mathrm{kHz})$ leading to peak cathode power densities of the order of several $\mathrm{kW} \mathrm{cm}^{-2}$, which is known to generate a dense and highly ionized plasma [12].

There have been reports on the usage of the power scheme from HiPIMS in PECVD for depositing $\alpha-\mathrm{Al}_{2} \mathrm{O}_{3}[13]$, using a parallel plate PECVD reactor. This study reported an increased hardness of the films deposited when using high-power pulses compared to conventional PECVD, which was attributed to a better cracking of the $\mathrm{AlCl}_{3}$ precursor by the higher plasma density, leading to lower chlorine incorporation in the films. Furthermore, a pure PVD process (sputtering) using a hollow cathode in combination with HiPIMS has been demonstrated to give high deposition rates of metallic films [14].

By using a highly ionized plasma in a PECVD process, the deposition conditions can be designed to provide a higher degree of energetic bombardment of the growing film. The energetic bombardment is achieved by applying a negative substrate bias at the substrate which will accelerate the positively charged ions in the plasma towards the substrate. Such a bombardment is highly important for deposition of $\mathrm{sp}^{3}$-hybridized films like cubic boron nitride [15] and diamond like carbon [16].

In this paper, a novel PECVD thin film deposition process, based on a hollow cathode discharge plasma and a power scheme using high-power pulses, is presented and applied to 
deposit copper containing amorphous carbon films at an exceptionally high deposition rate. Thin films of amorphous carbon $(\mathrm{a}-\mathrm{C})$ are today among the most promising multi-functional material systems for a number of industrial applications, e. g. hard coatings, biomedical coatings and MEMS devices [17]. Furthermore, copper containing a-C films, with copper content as high as 77 at\%, have previously been studied and promising tribological and antibacterial properties have been reported $[18,19,20]$. The grown thin films have been characterized in order to investigate the elemental composition, microstructure as well as hardness. The results are also correlated to the plasma conditions as studied by optical emission spectroscopy.

\section{Experimental details}

The novel PECVD reactor developed in this study, Fig. 1, consisted of a reaction chamber made of stainless steel, which was pumped by a turbo molecular pump to a background pressure of less than 0.1 mTorr. The hollow cathode was placed in the top lid of the reaction chamber over the substrate. A hollow cathode made of copper was chosen due to the high electrical conductivity, but in principal any conducting material could be used. The diameter and length of the hollow cathode was 5 and $85 \mathrm{~mm}$, respectively, which gives an inner cathode area of $1340 \mathrm{~mm}^{2}$. Argon gas (minimum purity of 99.9997\%) was fed through the hollow cathode enabling a brightly glowing argon plasma jet extending approximately 10 $\mathrm{mm}$ from the hollow cathode towards the substrate. The argon flow is controlled by a mass flow controller set at $84 \mathrm{sccm}$ throughout the entire study. For the carbon films deposited in this study, acetylene $\left(\mathrm{C}_{2} \mathrm{H}_{2}\right)(99.6 \%)$ was used as precursor. The precursor gas flow was controlled by a mass flow controller and was fed from the side into the plasma jet. The total 
process pressure was adjusted by a throttle valve. In this work the pressure was varied between 450 - 550 mTorr. The cathode-substrate distance can be modified by moving the sample holder. In this work a cathode-substrate distance of $20 \mathrm{~mm}$ was used.

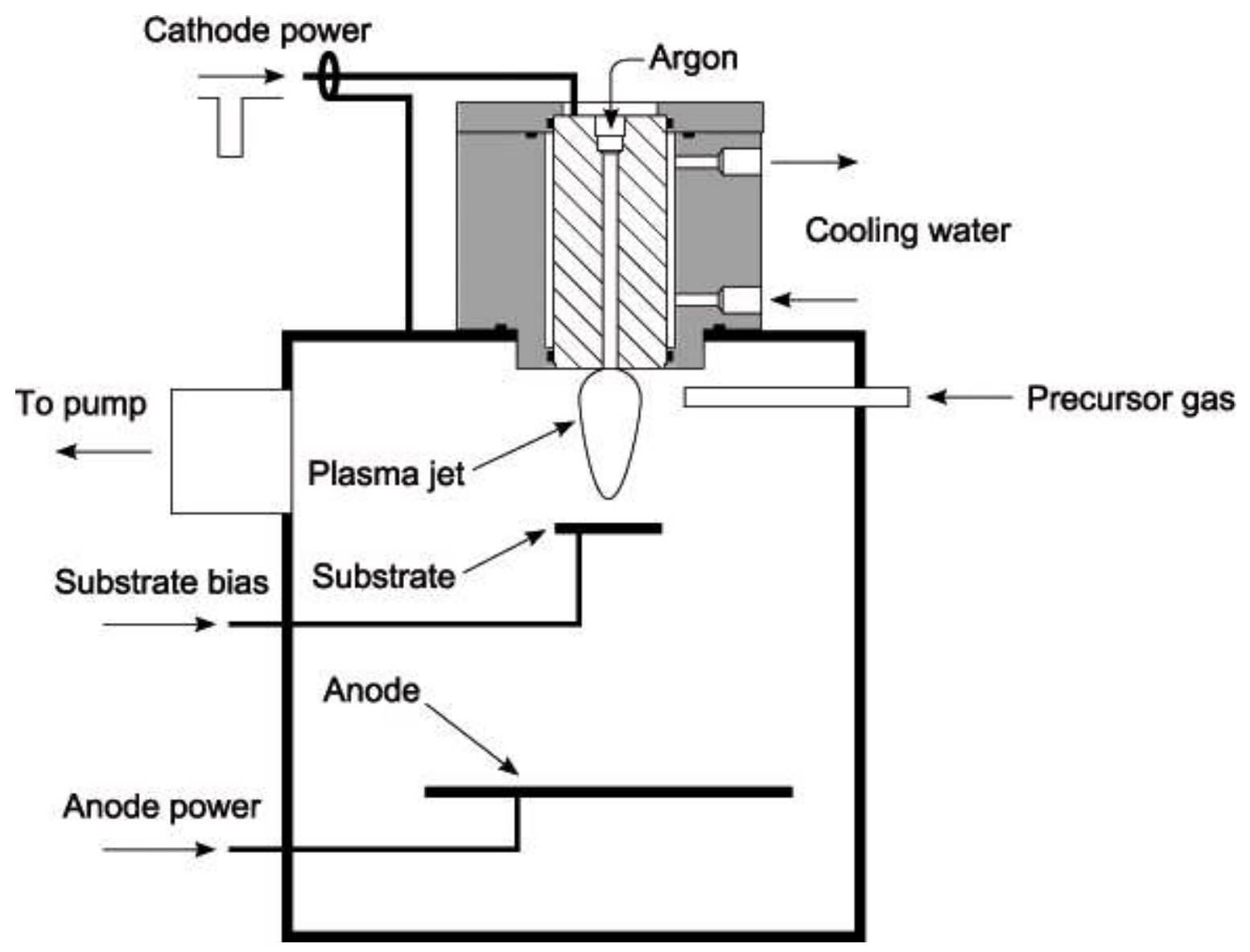

Figure 1: Schematics of the hollow cathode PECVD reactor.

To ignite the hollow cathode plasma, either DC power or a combination (superposition) of DC and high-power pulses (HiPP) was used by connecting one DC power supply (MDX 500, Advanced Energy) and one high-power pulsed power supply ( $\mathrm{HiP}^{3}$, Ionautics) in parallel. In the HiPP + DC mode the DC power supply was isolated from the HiPP power supply by a series diode between DC supply and cathode. For pure DC processes, only the DC power supply was connected to the hollow cathode. The discharge parameters, such as cathode voltage, $U_{D}$, and cathode current, $I_{D}$, was monitored and recorded on a Tektronix TDS2004B 
oscilloscope. PECVD processes using a total applied average power of 50-200 W in DC or HiPP + DC mode were studied. The reason for using a superposition of HiPP + DC and not only HiPP is that it facilitates the ignition of the plasma and thus leading to more stable operating conditions. Pulses of approximately $-450 \mathrm{~V}$ and $12 \mathrm{~A}$ were used with a pulse duration of $30 \mu$ s and a repetition frequency of $500 \mathrm{~Hz}$ (see Fig. 2). These discharge conditions resulted in an average HiPP power of $30 \mathrm{~W}$ to the cathode and the total input power was varied by adjusting the DC power.

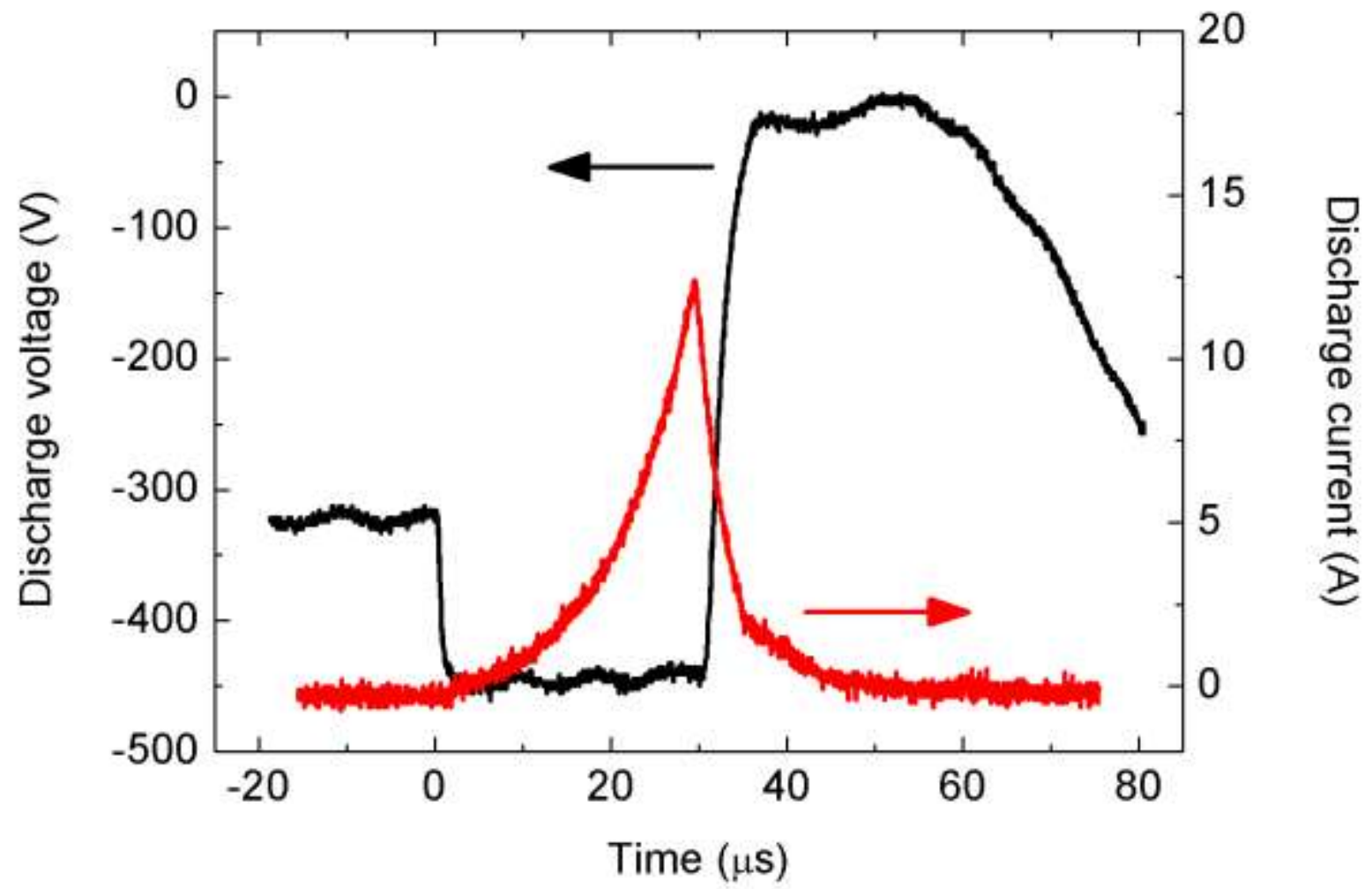

Figure 2: A typical superimposed DC + HiPP discharge pulse used in the present study. The applied DC voltage is about $-320 \mathrm{~V}$ as can be seen before the onset of the HiPP (at $t=0 \mu \mathrm{s}$ ).

A spectrometer (Mechelle Sensicam 900) connected to a collimator via an optical fiber was used to record the emission from the plasma. The spectral range of the spectrometer was 
300-1100 nm. Time-averaged optical emission was recorded from a volume of plasma located between the cathode and the substrate.

Single crystalline (100) silicon wafers, cut into approximately $2 \times 2 \mathrm{~cm}^{2}$ pieces, were used as substrates. The substrates were ultrasonically cleaned in ethanol for 10 minutes and blow dried in dry nitrogen before loading them into the deposition chamber. Prior to deposition the substrates were plasma etched in a pure argon atmosphere at $45 \mathrm{mTorr}$, by applying a large negative pulsed bias with a frequency of $\sim 100 \mathrm{kHz}$ to the substrate holder, giving a selfbias voltage of about $-600 \mathrm{~V}$. During deposition the ions in the plasma were directed towards the substrate surface using the same negative pulsed bias. In this case the self-bias voltage was varied in the range $-16 \mathrm{~V}$ to $-200 \mathrm{~V}$, leading to an intense ion bombardment during film growth. The plasma was further guided towards the substrate by the position of the anode placed below the substrate holder; an anode bias of $+40 \mathrm{~V} D C$ was used throughout this study.

The thickness and microstructure of the films were studied using a LEO scanning electron microscope (SEM) on cleaved samples. The film hardness was investigated by nanoindentation (UMIS-2000, Fischer-Cripps Laboratories). Time of flight-energy elastic recoil detection analysis (ToF-E ERDA) was used to determine the elemental composition in the films using $32 \mathrm{MeV}$ iodine ions. The experimental details of the ToF-E ERDA can be found elsewhere [21].

\section{Results and Discussion}

\subsection{Plasma characteristics}


The novel PECVD process was run in both DC as well as HiPP + DC mode varying the average power between $50-200 \mathrm{~W}$. In Fig. 2 a typical discharge pulse is given when pulsing the hollow cathode. In general, the peak current and power increase from about $0.5 \mathrm{~A}$ and 150 W in the DC case to $12 \mathrm{~A}$ and $1100 \mathrm{~W}$ in the HiPP + DC mode, although the time-average power is kept on a DC level. The instantaneous increase of applied power to the cathode during the discharge pulse (leading to an increased amount of charge carriers) is known to generate a denser plasma [22] and thereby an increased probability for the neutral species $\left(\mathrm{Ar}, \mathrm{C}_{\mathrm{x}} \mathrm{H}_{\mathrm{y}}\right.$, and $\left.\mathrm{Cu}\right)$ to undergo electron impact ionization. By using optical emission spectroscopy it was possible to investigate in more detail the changes in the degree of ionization between the different discharge configurations. Fig. 3 shows a comparison between optical emission spectra taken from a DC discharge and a HIPP + DC discharge. In Fig. 3a-b the total average discharge power was $150 \mathrm{~W}$. In order to increase the effect of the HiPP process the average power was decreased to $70 \mathrm{~W}$, while still keeping the HiPP contribution to $30 \mathrm{~W}$, see Fig. 3c. Note that the vertical scale in Fig. 3 is arbitrary and independent of each other, which means that quantitative comparisons cannot be made. However, there are significant qualitative differences between the different cases: 1 ) The pure DC discharge shows large fractions of neutral copper (Cu I) seen in the regions $\lambda \sim 324$ $327 \mathrm{~nm}, \lambda \sim 510-523 \mathrm{~nm}$ and $\lambda \sim 578 \mathrm{~nm}$, whereas the emission from the HiPP + DC discharges also show singly ionized copper (CU II) in the region $\lambda \sim 404-420 \mathrm{~nm}$ [23]. This is particularly striking in Fig. 3c, where the HiPP contribution to the overall discharge is considerably higher. 2) Emission of singly ionized argon (Ar II) is only found in the HiPP + DC mode, which can be seen in Fig. $3 c$ at $\lambda \sim 428-437 \mathrm{~nm}$ and at $\lambda \sim 459-473$. 3) Emission of singly ionized carbon (C II) is only found in the HiPP + DC mode, which is most clearly seen at $\lambda \sim 658 \mathrm{~nm}$, but also at $\lambda \sim 426-427 \mathrm{~nm}$ (Fig. 3c) [23]. As can be seen in all cases there is 

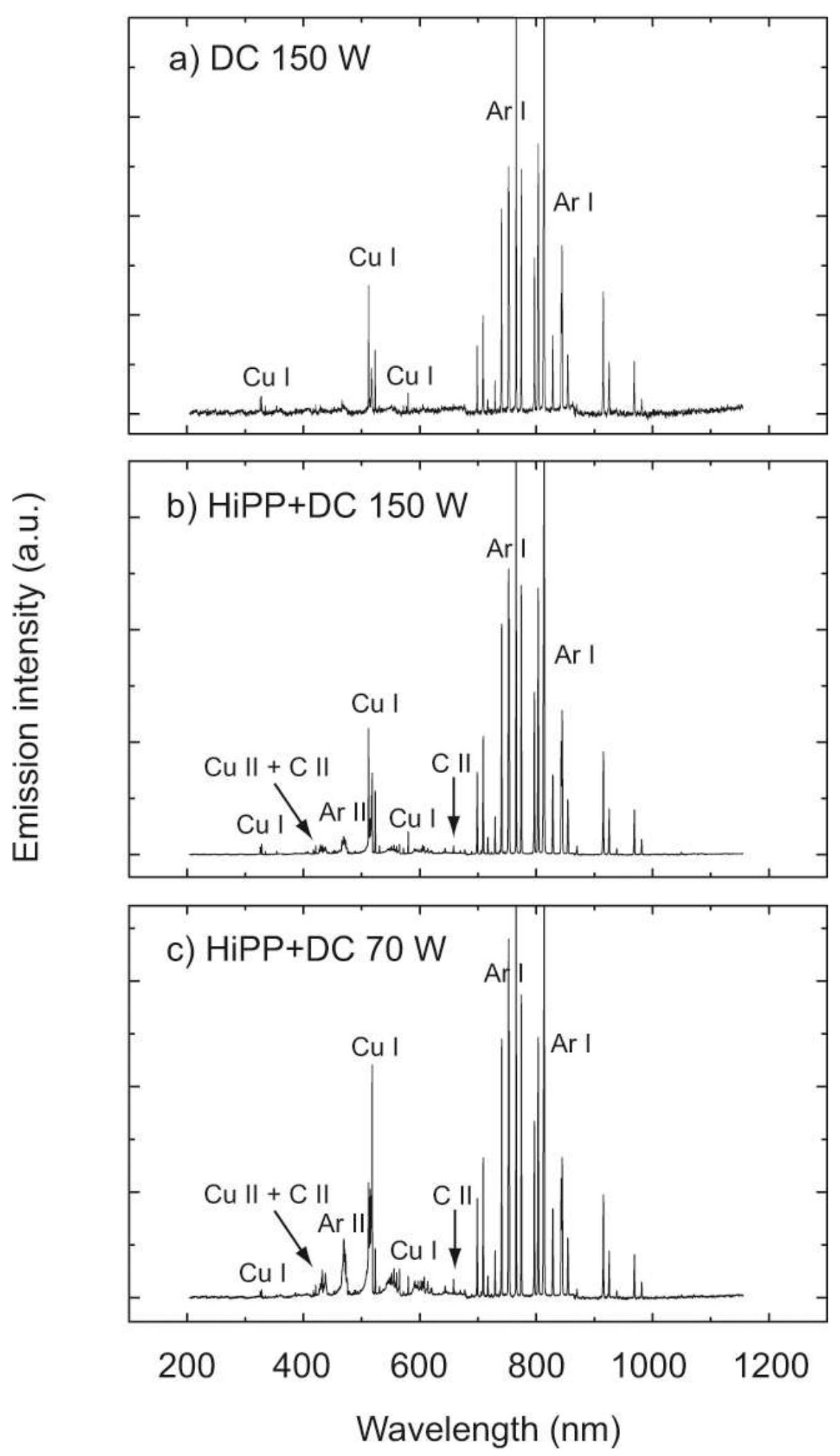

Figure 3: Optical emission spectra taken from a) a DC discharge at an average power of 150 W, b) a HIPP + DC discharge at an average power of $150 \mathrm{~W}$, and c) a HIPP + DC discharge at an average power of $70 \mathrm{~W}$. The different regions indicating neutral and ionized species are given. 
strong emission from neutral argon (Ar I) $(\lambda \sim 696-980 \mathrm{~nm})$ [23]. No clear evidence of neutral carbon (C I) was found, although there are some emission intensity around $600-602$ $\mathrm{nm}$ in Fig. 3b-c, which could be attributed to the presence of $\mathrm{CI}$. However, this could also be due to $\mathrm{Cu}$ II found at $\lambda \sim 600 \mathrm{~nm}$ [23]. Furthermore the lack of $\mathrm{CI}$ spectral lines may be due to that the relative intensity of the $\mathrm{Cl}$ emission is at least an order of magnitude lower compared to $\mathrm{Cu}$ I and $\mathrm{Ar} I$ [23]. Neutral H (H I) was not detected. The detected intensity peak at $\lambda \sim 658 \mathrm{~nm}$ (C II) seen in Fig. 3c is however fairly close to $\lambda \sim 656 \mathrm{~nm}(\mathrm{HI})$, but none of the other strong peaks indicating $\mathrm{HI}$, such as $\lambda \sim 389 \mathrm{~nm}$ or $\lambda \sim 486 \mathrm{~nm}$, were found.

From the results presented above it can be concluded that the HiPP + DC mode generally provides a more ionized plasma with respect to both the sputtered metal atoms as well as the process and precursor gases. This is likely caused by an increase in plasma density and possibly also electron temperature [24]. Until firmer experimental investigations on the plasma conditions, such as Langmuir probe characterization and mass spectrometry, of this type of PECVD process has been made no quantitative conclusions can be drawn.

\subsection{Deposition process characteristics}

The deposition rate for various input powers with a constant acetylene flow is shown in Fig.

4. It can be seen that the deposition rate increases linearly with input power up to $\sim 150 \mathrm{~W}$. For higher input powers the deposition rate is constant. This suggests that at the precursor flow studied here $\left(3 \mathrm{sccm} \mathrm{C}_{2} \mathrm{H}_{2}\right.$ ), an input power of $150 \mathrm{~W}$ is needed to use the precursors efficiently, regardless of power scheme used. It is interesting to note that for the whole input power range studied, a higher deposition rate is obtained when using a combination of HiPP and DC power. This suggests that the pulsed power scheme leads to a more effective 
use of the precursors, possibly due to the higher plasma density in the HiPP + DC plasma. It has previously been noted for amorphous carbon films deposited from acetylene by ECRPECVD that the deposition rate increases with ion current density [25]. It is thus likely that the greater amount of ionized species present in the HiPP + DC mode, as observed in section 3.1 , contributes to the approximately $20 \%$ increase of the deposition rate compared to the pure DC mode for the same average input power.

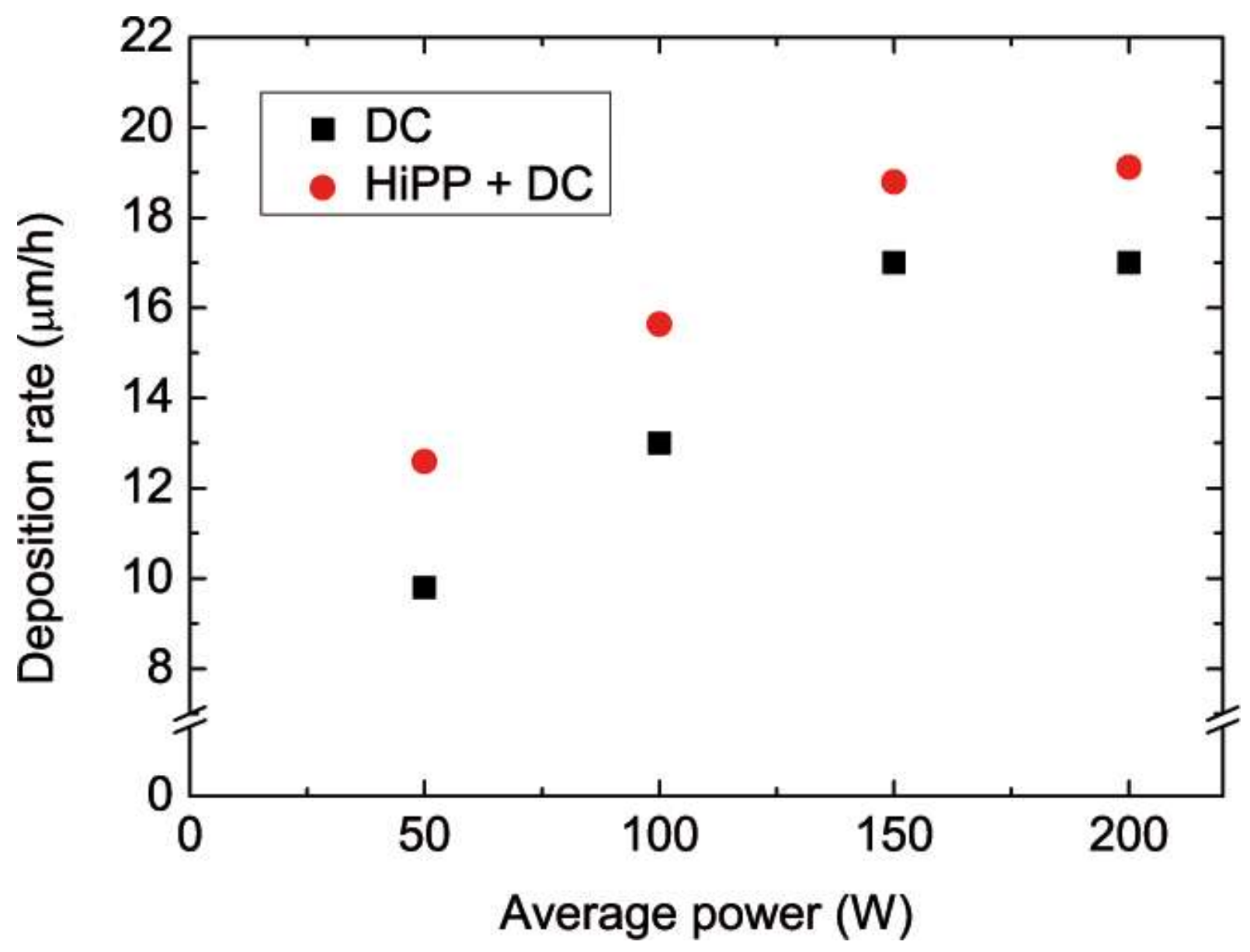

Figure 4: Deposition rate for different input power using DC power (squares) and HiPP + DC (circles) for a constant $\mathrm{C}_{2} \mathrm{H}_{2}$ flow of $3 \mathrm{sccm}$.

The changes in deposition rate when changing input acetylene flow rate is shown in Fig. 5. The deposition rate is found to increase linearly with increasing precursor flow in the 
precursor flow range studied. It can also be noted that the deposition rate is slightly higher when using HiPP + DC power compared to using DC power. This is a further indication that the pulsed power leads to increased plasma reactivity, increased cracking of the precursor gases, and ultimately a more efficient PECVD process.

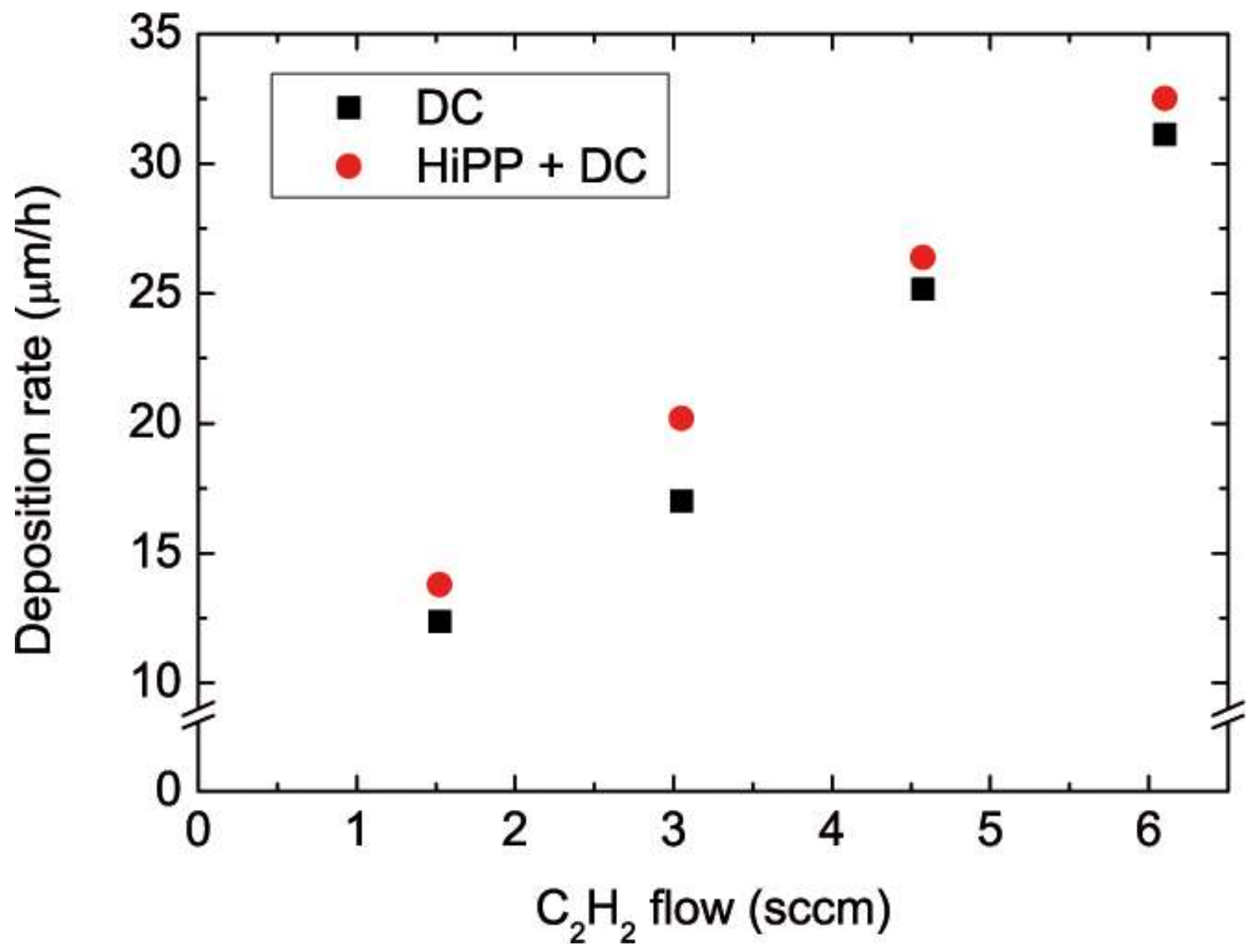

Figure 5: Deposition rate for different input $\mathrm{C}_{2} \mathrm{H}_{2}$ flow rates using DC (squares) and HiPP + DC (circles) for a constant input power of $150 \mathrm{~W}$.

\subsection{Film characteristics}

The deposited amorphous, copper containing carbon films all appear dense in cross sectional SEM (Fig. 6). From ToF-E ERDA, it was found that the films contained 30-50 at\% copper, emanating from sputtering of copper from the hollow cathode. The amount of copper in the 


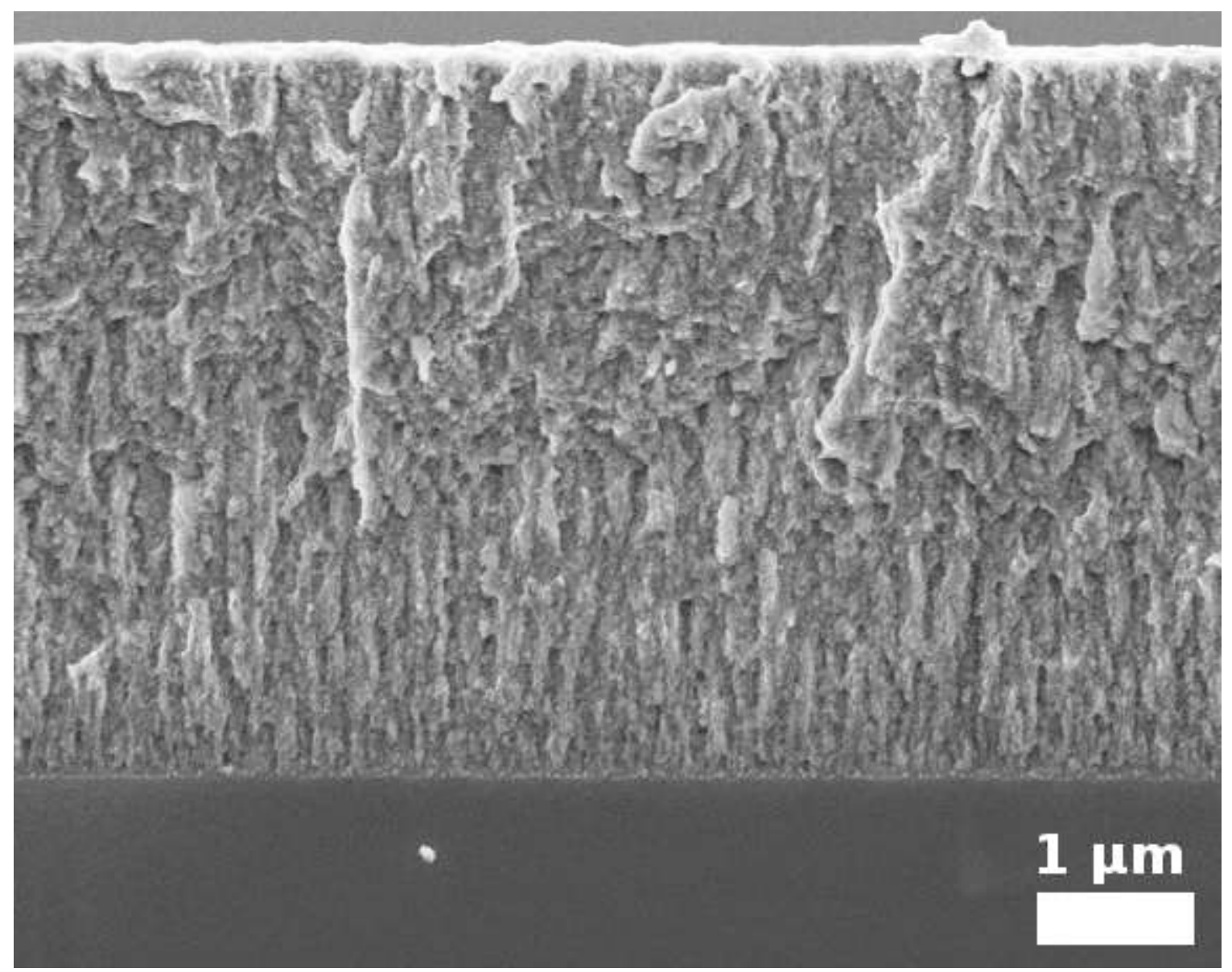

Figure 6: Cross section SEM micrograph of an XRD amorphous carbon film deposited at 20 $\mu \mathrm{m} / \mathrm{h}$ with $3 \mathrm{sccm} \mathrm{C}_{2} \mathrm{H}_{2}$ and input power of $150 \mathrm{~W} \mathrm{HiPP}+\mathrm{DC}$.

films was found to decrease with higher deposition rate, achieved by higher input power

(Fig. 4). Also by using HiPP + DC, less copper was incorporated in the films compared to when using pure DC. This is somewhat surprising given the higher ionization of the plasma when HiPP + DC were used. It could be speculated that the higher ionization of the plasma gives an increased ion bombardment of the film which might lead to a preferential resputtering of the copper atoms. Another possibility is back-attraction of copper ions to the negatively charged cathode [26], hence decreasing the metal flux to the substrate. Naturally, 
the amount of sputtered atoms from the cathode is highly dependent of the sputter yield of the cathode material used and a cathode material suitable for the deposited thin film should be used. However, the sputtering of atoms from the cathode suggests that the presented PECVD method could be used for processes that use atoms both sputtered from a solid material and released by chemical reactions from gases. Such processes can be regarded as hybrids of CVD and PVD and could be beneficial for depositing films containing metals for which the standard CVD precursors are undesirable to use due to e.g. high price, high toxicity or that the precursor molecule contains atoms detrimental to the film. From the ERDA measurements it was also concluded that the hydrogen content in the films was 4-5 at\% which is significantly lower than recently reported hydrogen content of $20-35$ at\% for amorphous carbon films, free from copper, deposited by PECVD [27]. The reason for hydrogen elimination is likely to be a combination of large energy fluxes to the substrate, which will raise the substrate temperature as well as ion bombardment of the growing film resulting in preferential removal of hydrogen $[1,28]$. The hardness of the films was in the order of $5 \mathrm{GPa}$, which is expected, since the copper content is fairly high in all the deposited samples and thus reducing the hardness [29]. Further optimization of the coating properties will be the aim of a future study.

The applied substrate AC bias was observed to have a significant impact on the film microstructure as seen in Fig. 7, where different substrate bias has been used during film deposition. The deposition was first done for 5 minutes with -200 V AC bias and resulted in $1.2 \mu \mathrm{m}$ film, corresponding to a deposition rate of $14 \mu \mathrm{m} / \mathrm{h}$, with a fairly dense, noncolumnar microstructure. The substrate bias was then decreased to $-100 \mathrm{~V}$ AC with continued deposition for an additional 5 minutes resulting in $1.6 \mu \mathrm{m}$ film, corresponding to $19 \mu \mathrm{m} / \mathrm{h}$, with a less dense microstructure. Finally, the substrate bias was adjusted to $-16 \mathrm{~V}$ 
AC which after 5 minutes deposition yielded $2.3 \mu \mathrm{m}$ film, which gives a deposition rate of

$27 \mu \mathrm{m} / \mathrm{h}$, with a highly porous, columnar microstructure.

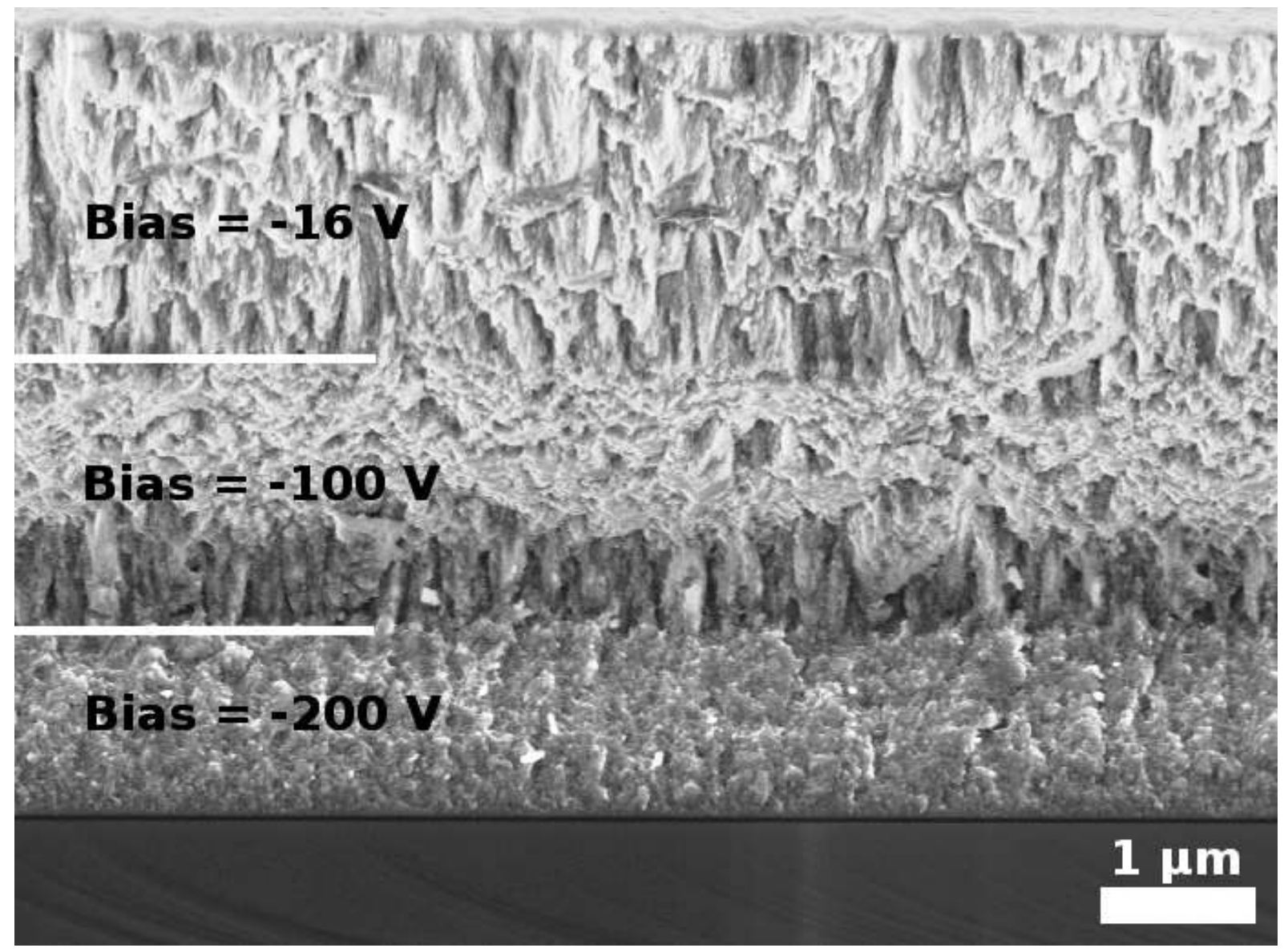

Figure 7: Cross section SEM micrograph of a film deposited at three different substrate bias values $(-16 \mathrm{~V},-100 \mathrm{~V}$, and $-200 \mathrm{~V})$ to study the effect of the substrate bias on the microstructure and deposition rate of the film. Deposition was done for 5 minutes for each substrate bias with an acetylene flow of $6 \mathrm{sccm}$ and an input power of $150 \mathrm{~W}$ HiPP + DC.

The initially high negative bias voltage used, leads to an increased kinetic energy of the charged particles bombarding the film surface, which is known to generate a denser, less columnar structure, where re-nucleation commonly takes place [30]. As the substrate bias voltage is reduced the growth mode is shifted towards an under-dense columnar morphology due to limited surface diffusion. Worth noting is that the best results regarding hardness stems from deposition processes using -200 V. 


\section{Concluding remarks}

A novel PECVD method based on a hollow cathode discharge has been presented and used for high rate deposition of amorphous, copper containing carbon thin films. The study presented shows that by applying a combination of high power pulses (HiPP) and DC power to the cathode, a plasma-based process that uses the precursor gases more efficiently is obtained. It is likely an effect of an increased plasma density resulting in an increased degree of ionization of the sputtered metal atoms as well as the process and precursor gases compared to a pure DC discharge. This PECVD method further has the ability to supply atoms for the films also by sputtering from the hollow cathode and it is thereby potentially interesting for processes using metals for which standard CVD precursors are undesirable e.g. due to their toxic or expensive nature.

\section{Acknowledgements}

Financial support from the Swedish innovation agency (VINNOVA) and Ångpanneföreningens forskningsstiftelse (ÅForsk) is gratefully acknowledged. lonautics AB is gratefully acknowledged for providing a $\mathrm{HiP}^{3}$ power supply. 


\section{References}

[1] W. Hess, D. B. Graves in: M. L. Hitchman, K. F. Jensen (Eds.) Chemical Vapor Deposition: Principles and Applications, Academic Press Ltd, San Diego, 1993, pp. 385-435.

[2] L. Martinu, O. Zabeida, J. E. Klemberg-Sapieha in: P. M. Martin (Ed.) Handbook of Deposition Technologies for Films and Coatings, 3rd edition, Elsevier, Amsterdam, 2010, pp. $392-465$.

[3] S. E. Alexandrov, M. L. Hitchman in: A. C. Jones, M. L. Hitchamn (Eds.) Chemical Vapour Deposition: Precursors, Processes and Applications, Royal Society of Chemistry, Cambridge, 2009, pp. 494-534.

[4] A. D. White, J. Appl. Phys. 30 (1959) 711.

[5] H. Morgner, M. Neumann, S. Straach, M. Krug, Surf. Coat. Technol. 108-109 (1998) 513.

[6] D. Söderström, Doctoral Thesis: Modelling and Applications of the Hollow Cathode Plasma, Uppsala University, Uppsala, Sweden, 2008.

[7] H. Bolt, A. Buuron, F. Koch, M. Noethe, Surf. Coat. Technol. 108-109 (1998) 520.

[8] A. Hellmich, T. Jung, A. Kielhorn, M. Rissland, Surf. Coat. Technol. 98 (1998) 1541.

[9] D. Lusk, T. Casserly, M. Gupta, K. Boinapally, Y. Cao, R. Ramamurti, P. Desai, Plasma Process. Polym. 6 (2009) S429.

[10] J. Ni, W. Wu, X. Jin, X. Yang, Z. Chen, Y. Tang, Thin Solid Films 516 (2008) 7422.

[11] U. Helmersson, M. Lattemann, J. Bohlmark, A. P. Ehiasarian, J. T. Gudmundsson, Thin Solid Films 513 (2006) 1.

[12] D. Lundin, K, Sarakinos, J. Mater. Res. 27 (2012) 780.

[13] K. Jiang, K. Sarakinos, S. Konstantinidinis, J. M. Schneider, J. Phys. D 43 (2010) 325202. 
[14] R. Bandorf, D. Loch, G. Bräuer, 54th Annual Technical Conference Proceedings of the Society of Vacuum Coaters, p.155, Chicago, IL, April 16-21 (2011)

[15] I. Konyashin, J. Bill, F. Aldinger, Chem. Vap. Deposition 3 (1997) 239.

[16] J. Robertsson, Phys. Stat. Sol. A 205 (2008) 2233.

[17] J. Robertson, Mater. Sci. Eng. R 37 (2002) 129.

[18] C. C. Chen, F. C. N. Hong, Appl. Surf. Sci. 242 (2005) 261.

[19] R. M. Balestra, A. M. G. Castro, M. Evaristo, A. Escuderio, P. Mutafov, T. Polcar, A. Cavaliero, Surf. Coat. Technol. 205 (2011) S79.

[20] Y. H. Chan, C. F. Huang, K. L. Ou, P. W. Peng, Surf. Coat. Technol. 206 (2011) 1037.

[21] M. Junaid, D. Lundin, J. Palisaitis, C.-L. Hsiao, V. Darakchieva, J. Jensen, P. O. A. Persson, P. Sandstrom, W.-J. Lai, L.-C. Chen, K.-H. Chen, U. Helmersson, L. Hultman, J. Birch, J. Appl. Phys. 110 (2011) 123519.

[22] J.T.Gudmundsson, Vacuum 84 (2010) 1360.

[23] NIST Atomic Spectra Database (ver. 4.1.0) [Online]. Available: http://physics.nist.gov/asd [2012, January 20].

[24] J.A. Hopwood in: J.A. Hopwood (Ed.), Thin Films: Ionized Physical Vapor Deposition, Academic Press, San Diego, 2000, pp. 191-193.

[25] N. A. Morrison, S. E. Rodil, A. C. Ferrari, J. Robertson, W. I. Milne, Thin Solid Films 337 (1999) 71.

[26] D. J. Christie, J. Vac. Sci. Technol. A 23 (2005) 330.

[27] S. Peter, M. Günther, D. Hauschild, D. Grambole, F. Richter, Vacuum 85 (2010) 510.

[28] W. A. P. Claassen, W. G. J. N. Valkenburg, M. F. C. Willemsen, W. M. v. d. Wijgert, J. Electrochem. Soc. 132 (1985) 893. 
[29] Q. Wei, R. J. Narayan, A. K. Sharma, J. Sankar, J. Narayan, J. Vac. Sci. Technol. A 17 (1999) 3406.

[30] K. Sarakinos, J. Alami, S. Konstantinidis, Surf. Coat. Technol. 204 (2010) 1661. 